\title{
Combination of anti UV and soil resistant finishes for clothing of outdoor workers
}

\begin{abstract}
Clothing especially designed, fabricated, or treated to protect personnel against hazards caused by extreme changes in physical environment or dangerous working conditions is termed as 'protective clothing'. In the present study polyester/cotton blend in plain and twill weave were treated with two UV absorber and two soil-release finishes in combination to provide dual protection against sun rays and soil. The treated fabrics were tested for percent transmission of UVR which were measured using a fabricated instrument and the soiling and soil release characteristics were studied using a spectrophotometer. SEM studies were carried out on soiled fabrics before and after laundry. The results indicated the combination of Acacia catechu with $\mathrm{CMC}$ gave maximum protection as compared to other finishes in combination against UV rays as well soil removal.
\end{abstract}

Volume I Issue 6 - 2017

Rajni Yadav, Anjali Karolia

Department of Clothing and Textiles, the Maharaja Sayajirao University of Baroda, India

\begin{abstract}
Correspondence: Anjali Karolia, Professor and Head of Department, Department of Clothing and Textiles, Faculty of Family and Community Sciences, The Maharaja Sayajirao University of Baroda,Vadodara, Gujarat, India, Tel 098240I2643, Email anjalikaroli@hotmail.com
\end{abstract}

Received: April 05, 2017| Published: May 18, 2017

Keywords: ultraviolet radiation, percent transmission, whiteness index, soil-release, uv absorber, acacia catechu (katha), soil-release finishes, carboxy methyl cellulose

\begin{abstract}
Abbreviations: P/C-p, polyester/cotton-plain weave; P/C-t, polyester/cotton- twill weave; $\mathrm{U}_{\mathrm{A}}$, commercial UV absorber at $1 \%$ add-on; $\mathrm{U}_{\mathrm{B}}$, commercial $\mathrm{UV}$ absorber at $3 \%$ add-on; Uc, acacia catechu dyed at $2 \%$ shade; $\mathrm{U}_{\mathrm{D}}$, acacia catechu dyed at $4 \%$ shade; $\mathrm{S}_{\mathrm{AB}}$, commercial soil-release finishes; $\mathrm{S}_{\mathrm{C}}$, carboxymethyl cellulose at $1 \%$ add-on; $\mathrm{S}_{\mathrm{D}}$, carboxymethyl cellulose at $3 \%$ add-on; $\mathrm{O}_{\mathrm{A}}$, commercial UV absorber at $1 \%$ add-on+carboxymethyl cellulose at $1 \%$ add-on; $\mathrm{O}_{\mathrm{B}}$, commercial UV absorber at $1 \%$ add-on+commercial soil-release finishes; $\mathrm{O}_{\mathrm{C}}$, acacia catechu dyed at $4 \%$ shade+carboxymethyl cellulose at $1 \%$ add-on; $\mathrm{O}_{\mathrm{D}}$, acacia catechu dyed at $4 \%$ shade+commercial soil-release finishes
\end{abstract}

\section{Introduction}

Sunlight is the source of life on earth. Its spectrum extends from about $290 \mathrm{~nm}$ to $3000 \mathrm{~nm}$ consisting of UV (5\%), visible range $(50 \%)$ and infra-red $(45 \%)$ radiations, which penetrates through the protective ozone layer at a height of $10,000 \mathrm{~m}$ in stratosphere. The ultraviolet radiation (UVR) band consists of three regions: UV-A (320 to $400 \mathrm{~nm}$ ), UV-B (290 to $320 \mathrm{~nm}$ ), and UV-C (200 to $290 \mathrm{~nm}$ ). UV-A causing little visible reaction on the skin but has been shown to decrease the immunological response of skin cells. UV-B is most responsible for the development of skin cancers. The highest energy UV-C, which is the most dangerous to skin, is fortunately filtered by the ozone layer. Due to polluting emissions, this ozone layer has got depleted by $5-10 \%$, forming the so called "ozone hole".

Behaviors that can reduce skin cancer risk include limiting or minimizing exposure to the sun during midday hours when UV radiation peaks (10am to $4 \mathrm{pm}$ ); Exposed area of skin should be covered by working clothes with low UVR transmission; and using appropriate sunscreen protection. Although sunscreen is thought to be an important adjunct to other types of UV protection, it should not be counted on to provide UV protection by itself.

Outdoor workers also may spend more time outdoors during their time off, and therefore expose their skin to high doses of ultraviolet radiation. It is common for outdoor workers to spend many years in their occupations, so their exposure to intense UV rays occurs throughout their lives. ${ }^{2}$ Along with exposure to sun rays, pollution causes soiling problem in the working clothes of the outdoor workers, as they work in the open and are exposed to higher level of dirt and grime. Accumulation of foreign material often results in discoloration, changes in appearance and loss of fabric luster. ${ }^{3}$ The best defense against sun-rays and pollution is the constant use of suitable protective clothing.

Polyester/cotton fabrics have been used widely for uniforms of outdoor workers because care and laundry of polyester/cotton blend ratio $67 / 33$ provides a balance of properties to give optimum performance for uniforms and is comfortable for wear even in warm weather. ${ }^{4}$ Addition property of protection against ultraviolet radiation and soiling can be synergized when treated with UV absorbers and soil-release finishes. In this study, two UV-absorbers and two soilrelease finishes in four combinations have been studied on polyester/ cotton blend fabrics.

\section{Materials and methods}

\section{Fabrics}

Polyester/cotton blend $67 / 33 \%$ in plain and twill were selected such that they could be used as upper and lower garments for the outdoor workers. All the fabrics were scoured with $2 \mathrm{~g} / \mathrm{l}$ detergent and $2 \mathrm{~g} / \mathrm{l}$ sodium carbonate at $80^{\circ} \mathrm{C}$ for $45 \mathrm{mins}$. The material to liquor ratio was maintained at 1:40. The fabrics were thoroughly washed and then air dried.

\section{Determination of preliminary data}

Fabric parameters including fiber type, mass, fabric count, structure, thickness and cover factor were determined and has been shown in Table 1.

\section{Fabric treatments}

Two UV-absorber finishes i.e. Commercial UV absorber and Acacia catechu (Katha) and two soil-release finishes i.e. Commercial 
soil-release finish and Carboxyl Methyl Cellulose were selected for study. The combination of UV absorber and soil-release finishes were applied on to the polyester/cotton fabrics to provide dual protection against ultraviolet radiation and soil. In pilot study fabrics were padded with commercial UV absorbers and Carboxymethyl cellulose (C.M.C) at $1 \%\left(\mathrm{U}_{\mathrm{A}}\right)$ and $3 \%\left(\mathrm{U}_{\mathrm{B}}\right)$ add-on. All the fabrics were

Table I Preliminary data of the fabrics coloured using exhaust and H.T.H.P. method for cotton and polyester, polyester/cotton blend respectively with Acacia Catechu at $2 \%\left(\mathrm{U}_{\mathrm{C}}\right)$ and $4 \%\left(U_{D}\right)$ shades. It was found that the commercial UV absorber $1 \%$ add-on gave similar results as compared to $3 \%$ add-on and in case of natural colourant $4 \%$ shade gave better results than $2 \%$ shade.

\begin{tabular}{llllll}
\hline Fabric & $\begin{array}{l}\text { Fabric } \\
\text { code }\end{array}$ & Total fabric count $(\mathbf{c m})$ & Cloth cover & Thickness $(\mathbf{m m})$ & Wt/unit area $\left(\mathbf{g} / \mathbf{m}^{2}\right)$ \\
\hline Polyester/cotton-plain weave & P/C-p & 84 & 24.97 & 0.24 & 122.11 \\
Polyester/cotton- twill weave & P/C-t & 77 & 28.83 & 0.44 & 274.43
\end{tabular}

In the case of soil-release finishes, CMC treated cotton at $3 \%$ add-on gave better results. Polyester plain and twill weave fabrics showed better result with commercial soil-release finishes. However polyester/cotton blend fabric gave similar results with both the finishes i.e. commercial soil-release finishes and CMC. Polyester/cotton blend plain and twill weave fabrics gave good results with both the soilrelease finishes i.e. commercial soil-release finish and CMC at both the add-on. After analysis of results four optimum combination were purposively selected and applied on Polyester/Cotton blend.

The combinations were with lower add-ons as with the higher addon not much improvement in properties was seen as well as when two finishing treatments were to be given together the higher addon's would increase the weight of the fabrics under study. However the natural colourant Acacia Catechu higher percent shade of $4 \%$ was selected as higher \% shade gave better result against UV radiation.

The four combinations studied were as follow:

a. $\mathrm{O}_{\mathrm{A}}$ : Commercial UV absorber at $1 \%$ add-on+Carboxymethyl cellulose $1 \%$ add-on

b. $\mathrm{O}_{\mathrm{B}}$ : Commercial UV absorber at $1 \%$ add-on+Commercial soil-release finishes

c. $\mathrm{O}_{\mathrm{C}}$ : Acacia catechu dyed at $4 \%$ shade + Carboxymethyl cellulose at $1 \%$ add-on

d. $\mathrm{O}_{\mathrm{D}}$ : Acacia catechu dyed at $4 \%$ shade + Commercial soil-release finishes

Above four combinations were applied to the polyester/cotton plain and twill fabrics.

\section{Application procedure}

Commercial UV absorber $\left(\mathbf{U}_{\mathbf{A B}}\right)$ : Commercial UV absorber finishes $\mathrm{A}$ and $\mathrm{B}$ were applied on the fabric sequentially one after the other with the help of padding mangles. The recipe followed was as follow:

A. Recipe of commercial UV absorber 'A'

i.Padliquor: $40 \mathrm{gm} / 1$

ii. Sodium Carbonate/ Soda ash: $(3.75+0.123 * 40) \mathrm{g} / 1$

iii. Urea: $60 \mathrm{gm} / 1$

B. Recipe of commercial UV absorber ' $\mathrm{B}$ '
i. Padliquor: $30 \mathrm{~g} / 1$
ii. Commercial Auxiliary 'A': 20g/l
iii. Commercial Auxiliary 'B':1g/1

Dyeing with acacia catechu with simultaneous mordanting method $\left(\mathbf{U}_{\mathrm{D}}\right)$ : Dyeing of polyester/cotton blend was dyed on laboratory glycerin dye bath machine, Model No. $25000 \times 12$ of Tex-Fab Engineers (India) Pvt. Ltd. The material liquor ratio was 1:40. The fabric were then removed after $45 \mathrm{~min}$ of dyeing, washed with cold water, soaped at $40^{\circ} \mathrm{C}$ for $10 \mathrm{~min}$ with non-ionic detergent, rinsed and air-dried.

Commercial soil-release finishes $\left(S_{A B}\right)$ : Polyester/cotton blended fabrics treated with combination of chemical $\mathrm{A}$ and $\mathrm{B}$, which were taken as per the $\%$ of the fibre content in the blended fabrics. Fabrics were treated by pad-dry-cure process and then fabrics were kept in oven for $30 \mathrm{sec}$ at $180^{\circ} \mathrm{C}$ for fixation of chemical with fabric.

Carboxymethyl cellulose (C.M.C) (S): A homogenous mixture of $1 \% \mathrm{CMC}$ at boil was prepared in water. The fabrics were padded with a single nip and dip using a laboratory 2-bowl padding mangle at $1.5 \mathrm{~kg} / \mathrm{cm}^{2}$ pressure. Sample were subsequently dried at room temperature and then cured at $100^{\circ} \mathrm{C}$ for $5 \mathrm{~min}$.

\section{Evaluation of finishes}

For UV absorber: Before and after the applications of finishes fabrics were tested to determine percent UVR transmission using fabricated instrument, based on direct optics using UV diode in the laboratory. Other properties like durability of UV absorbers to laundering (3 wash cycles) and perspiration (artificial acidic and alkaline) were also studied using standard test method.

Fabrication of instrument for evaluation of UV transmission: The instrument was based on direct optics Figure 1. Light was generated through a tungsten halogen lamp (Its intensity is closely matches the solar spectrum. The light passes through the monochromator). Mono chrometer only passes UV rays with particular wavelength. Optical chopper converts this UV rays into pulses and the alternating current passes through the concave mirror to focus the light. The light is directed towards the plane mirror from where the light passes on the fabric where the transmitted light is detected by a UV diode (It respond similarly to human skin) It allow the flow of current in one direction toward the lock in amplifier, which amplifies that signal to certain level converting $0-5 \mathrm{~V}$ signal to computer. The fabric sample was placed $0.05 \mathrm{~cm}$ away from the UV diode. The whole set up was programmed on the computer by the Lab view 7.1 software. The computer screen directly showed the graph between wavelength and transmittance and transmittance percentage was calculated by the following formula:

$$
\text { UVR Transmission } \%=\frac{\text { Transmission obtained by Fabric }}{\text { Transmission of Direct Light }}
$$




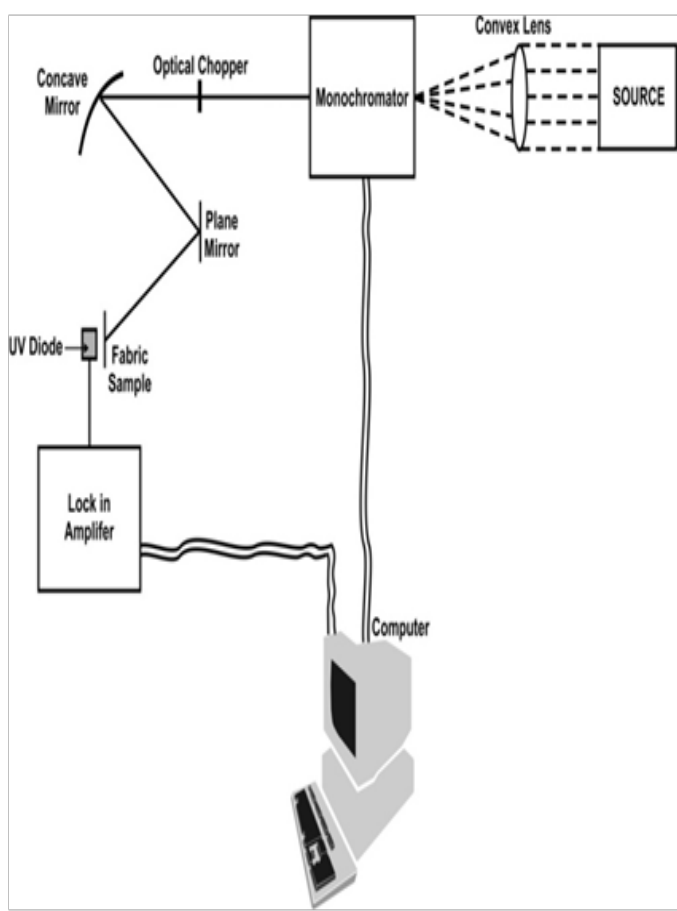

Figure I Schematic Diagram of Fabricated Instrument for Testing UV Transmission.

Determination of percent UVR transmission of untreated and treated fabrics after exposure to artificial perspiration: The clothing worn by outdoor workers would be exposed to perspiration during wear and so it was thought to study the effect of perspiration on the UV protection of the finished fabrics. The moisture content of a fabric could increase during wear due to atmospheric condition and perspiration which in turn may affect the fabric's capability of protecting the skin from solar UV radiation. The water absorption of the fabric depends on the fiber content like cotton, polyester and acrylic etc. Therefore the effect of fabric wetness due to artificial perspiration on UV percent transmission was investigated.

Procedure: Samples of $10 \times 4 \mathrm{~cm}$ were taken and the samples were treated with the artificial perspiration, Recipes for the same are given below:-

Recipes for the preparation of alkaline and acidic solution:

\section{A. Alkaline Solution}

i. Distilled water: $1 \mathrm{~L}$

ii. 1-histidine-mono-hydro-chloride-mono-hydrate

iii. $\left(\mathrm{C}_{6} \mathrm{H}_{9} \mathrm{O}_{2} \mathrm{~N}_{3} \mathrm{HCl} . \mathrm{H}_{2} \mathrm{O}\right): 0.5 \mathrm{~g}$

iv. Sodium chloride: $5 \mathrm{~g}$

v. Disodium-hydrogen-orthophosphate-do-deca-hydrate

vi. $\left(\mathrm{Na}_{2} \mathrm{HPO}_{4} \cdot 12 \mathrm{H}_{2} \mathrm{O}\right): 5 \mathrm{~g}$

The solution was brought to $\mathrm{pH} 8$ by adding $0.1 \mathrm{~N}$ sodium hydroxide solution and stirred well.

\section{B. Acidic Solution}

i. Distilled water: $1 \mathrm{~L}$
ii. 1-histidine mono hydro chloride mono hydrate
iii. $\left(\mathrm{C}_{6} \mathrm{H}_{9} \mathrm{O}_{2} \mathrm{~N}_{3} \mathrm{HCl} . \mathrm{H}_{2} \mathrm{O}\right): 0.5 \mathrm{~g}$
iv. Sodium chloride: $5 \mathrm{~g}$
v. Sodium di hydrogen orthophosphate dihydrate
vi. $\left(\mathrm{NaH}_{2} \mathrm{PO}_{4} \cdot 2 \mathrm{H}_{2} \mathrm{O}\right): 2.2 \mathrm{~g}$

The solution was brought to $\mathrm{pH}$ of 5.5 by adding $0.1 \mathrm{~N}$ acetic solution and stir well.

Method: The untreated and treated fabrics were immersed in the separate bath of acid and alkali solution at room temperature for $30 \mathrm{~min}$ with occasional agitation to ensure thorough wetting out. The material liquor ratio of 1:40 was maintained. The wetted samples were then passed through the padding mangle with one nip at $2 \mathrm{~kg} / \mathrm{cm}^{2}$ weight to remove excess moisture.

For Soil-release finishes: The soiling and soil release characteristics of untreated and soil-release finish treated fabrics were studied. The fabrics were treated with artificial soiling (carbon black). After 3 wash cycles of laundering the whiteness characteristics were assessed by Hunter Whiteness Index under illuminate D65, 10 degree observer using a Spectra scan 5100 spectrophotometer. The percent soil uptake, percent soil-release and percent soil-redeposition were computed by the formulas using the whiteness index value and SEM studies were carried out on soiled fabrics before and after laundry.

Determination of percent UVR transmission and whiteness index of untreated and treated fabrics after laundering: Laundering of the finished samples was carried out in laboratory launder-o-meter IA 61-1962. The fabrics were cut into rectangular swatches. The samples were laundered using laboratory Launder-o-meter IA 61-1962. The cut samples of $10 \times 4 \mathrm{~cm}$ were placed in airtight jar containing $2 \mathrm{gm} / 1$ of non-ionic detergent solution. The M:L ratio was 1:40 with 10 stainless steel balls for abrasion and $45 \mathrm{~min}$ cycle was given at $40^{\circ} \mathrm{C}$. The samples were subjected for three such wash cycles. The samples were rinsed in water and air dried. Transmission measurements and whiteness index were done before and after treatment, so that each swatch served as its own control.

\section{Results and discussion}

The comparative results of the untreated and treated fabrics with the combination finishes have been given and discussed under the following subsection:

\section{Comparison and influence of finishes in combination on percent UVR transmission}

Effect of finishes in combination on polyester/cotton plain weave fabrics were studied for percent UVR transmission and UPF values.

It was seen from Table 2 the application of various finishes in combination, polyester/cotton blend plain weave fabrics showed lesser transmission than the untreated fabric, thus providing better protection.

It was also seen that when the fabrics was treated with the four combination finishes they gave better protection than the fabrics treated with the UV absorber individually.

Result also shows that the applications of UV absorbers with CMC $\left(\mathrm{O}_{\mathrm{A}}\right.$ and $\left.\mathrm{O}_{\mathrm{C}}\right)$ on polyester/cotton fabrics have more protection against 
ultraviolet radiation as compared to combination of $\mathrm{UV}$ absorbers with commercial soil-release finish $\left(\mathrm{O}_{\mathrm{B}}\right.$ and $\left.\mathrm{O}_{\mathrm{D}}\right)$.

Table 2 Percent UVR transmission of untreated and treated polyester/ cotton blend plain weave fabric with finishes in combination

\begin{tabular}{lllll}
\hline Treatments & $\%_{\text {UVA }}$ & $\%_{\text {UVB }}$ & $\%_{\mathrm{UVR}_{\mathrm{UV}}}$ & UPF values \\
\hline Untreated & 8.8 & 7.09 & 7.95 & 12.58 \\
UA & 5.14 & 4.48 & 4.81 & 20.79 \\
OA & 4.44 & 4.1 & 4.27 & 23.42 \\
OB & 4.36 & 4.36 & 4.36 & 22.94 \\
UD & 3.31 & 3.09 & 3.2 & 31.25 \\
OC & 2.57 & 2.31 & 2.44 & 40.98 \\
OD & 3.28 & 3.2 & 3.24 & 30.86 \\
\hline
\end{tabular}

$\cup_{A}$, Commercial UV absorber at $1 \%$ add-on; $U_{D}$, Acacia catechu dyed at $4 \%$ shade; $\mathrm{O}_{\mathrm{A}}$, Commercial UV absorber at $1 \%$ add-on+Carboxymethyl cellulose at $I \%$ add-on; $\mathrm{O}_{\mathrm{B}}$, Commercial UV absorber at $\mathrm{I} \%$ add-on+Commercial soil-release finishes; $O_{C}$,Acacia catechu dyed at $4 \%$ shade+Carboxymethyl cellulose at I\% add-on; $\mathrm{O}_{\mathrm{D}}$, Acacia catechu dyed at $4 \%$ shade+Commercial soil-release finishes.

Effect of launderings on percent UVR transmission of untreated and treated fabrics with combination of finishes on polyester/cotton blend plain weave fabric

The treated fabrics would have to undergo laundering as they would be used for the uniform of outdoor workers, so all the untreated and treated fabrics were subjected to laundry with non-ionic detergent and percent UVR transmissions were studied after 3cycles of laundry.

The Table 3 clearly showed that when the treated polyester/cotton plain weave fabric was laundered there was no noticeable change seen in the percent UVR transmission.

Table 3 Percent UVR transmission of polyester/cotton fabric after 3cycles of laundering

\begin{tabular}{|c|c|c|}
\hline \multirow[t]{2}{*}{ Treatments } & Before laundry & After laundry \\
\hline & $\% T_{\text {UVR }}$ & $\% \mathbf{T}_{\text {UVR }}$ \\
\hline Untreated & 7.95 & 6.91 \\
\hline UA & 4.81 & 4.59 \\
\hline OA & 4.27 & 4.56 \\
\hline OB & 4.36 & 4.37 \\
\hline UD & 3.2 & 3.11 \\
\hline OC & 2.44 & 2.68 \\
\hline OD & 3.24 & 3.08 \\
\hline
\end{tabular}

$\cup_{A}$, Commercial UV absorber at $I \%$ add-on; $U_{D}$, Acacia catechu dyed at $4 \%$ shade; $\mathrm{O}_{\mathrm{A}}$, Commercial UV absorber at $\mathrm{I} \%$ add-on+Carboxymethyl cellulose at $1 \%$ add-on; $O_{B}$, Commercial UV absorber at $1 \%$ add-on+Commercial soil-release finishes; $\mathrm{O}_{C}$, Acacia catechu dyed at $4 \%$ shade+Carboxymethyl cellulose at $1 \%$ add-on; $O_{D}$, Acacia catechu dyed at $4 \%$ shade+Commercial soil-release finishes

Similar results were seen when the combination finishes were compared to the UV absorber finishes when studied individually. However the combination with Acacia Catechu $\left(\mathrm{O}_{C}\right.$ and $\left.\mathrm{O}_{\mathrm{D}}\right)$ gave better results as compared to combination with Commercial UV absorber $\left(\mathrm{O}_{\mathrm{A}}\right.$ and $\left.\mathrm{O}_{\mathrm{B}}\right)$
Effect of perspiration on the percent UVR transmission of untreated and treated polyester/cotton blend plain weave fabric with finishes in combination

Perspiration affects the fabrics when worn and so its effect on percent UVR transmission values in acidic as well as alkaline perspiration were also studied.

Result of the percent UVR transmission of all the fabrics under study exhibited significantly lower protection when wet (with perspiration) as compared to fabric in dry state as shown in Table 4. The commercial UV absorber treated fabrics with commercial soilrelease finishes $\left(\mathrm{O}_{\mathrm{B}}\right)$ have less percent transmission as compared to commercial UV absorber $+\mathrm{CMC}\left(\mathrm{O}_{\mathrm{D}}\right)$ treated fabrics. Even in dyed samples same pattern was observed.

Table 4 Effect of perspiration on percent UVR transmission of untreated and treated fabric with finishes in combination

\begin{tabular}{|c|c|c|c|}
\hline \multirow[t]{3}{*}{ Treatments } & \multirow{3}{*}{$\begin{array}{l}\text { Dry state } \\
\% \mathrm{~T}_{\text {UVR }}\end{array}$} & \multicolumn{2}{|c|}{ Wet state (artificial perspiration) } \\
\hline & & Acid & Alkali \\
\hline & & $\% \mathbf{T}_{\text {UVR }}$ & $\% \mathbf{T}_{\text {UVR }}$ \\
\hline Untreated & 7.95 & 12.86 & 14.27 \\
\hline UA & 4.81 & 6.42 & 6.98 \\
\hline OA & 4.27 & 5.75 & 6.4 \\
\hline$O B$ & 4.36 & 6.91 & 7.24 \\
\hline UD & 3.2 & 6.06 & 6.17 \\
\hline OC & 2.44 & 5.99 & 6.57 \\
\hline OD & 3.24 & 5.11 & 6.01 \\
\hline
\end{tabular}

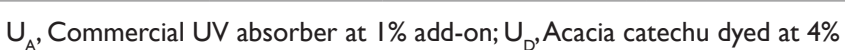
shade; $\mathrm{O}_{\mathrm{A}}$, Commercial UV absorber at $\mathrm{I} \%$ add-on+Carboxymethyl cellulose at $\mathrm{I} \%$ add-on; $\mathrm{O}_{B}$, Commercial UV absorber at $1 \%$ add-on+Commercial soil-release finishes; $O_{C}$, Acacia catechu dyed at $4 \%$ shade+Carboxymethyl cellulose at $1 \%$ add-on; $O_{D}$, Acacia catechu dyed at $4 \%$ shade+Commercial soil-release finishes.

It was also observed that even though percent UVR transmission increased in various combinations, treated fabrics still provided moderate protection as compared to untreated fabric which showed poor protection in wet state. It was also seen that in acidic perspiration the percent UVR transmission was lower as compared to alkaline perspiration.

\section{Comparison and effect untreated and treated fabric with finishes in combination on the soiling behavior}

Whiteness index of polyester/cotton blend fabrics without or with selected combinations after the application of artificial soiling and laundering ( 3 wash cycles) were evaluated using Spectrascan 5100 spectrometer and percent soil-uptake, percent soil-release and percent soil-redeposition were calculated based on whiteness index.

Percent soil-uptake: After the application of finishes percent soil uptake was more in untreated fabrics as compared to treated fabrics Table 5.

When the percent soiling of the four finishes in combination were compared it was seen that the combination with $\mathrm{CMC}\left(\mathrm{O}_{\mathrm{A}}+\mathrm{O}_{\mathrm{C}}\right)$ took 
more soil as compared to the combination which has commercial soil-release finish $\left(\mathrm{O}_{B}+\mathrm{O}_{D}\right)$. Also the commercial UV absorber combination i.e. $\mathrm{O}_{\mathrm{A}}$ and $\mathrm{O}_{\mathrm{B}}$ picked up more soil as compared to natural colorant in combination i.e. $\mathrm{O}_{\mathrm{C}}$ and $\mathrm{O}_{\mathrm{D}}$.

Table 5 Percent soiling with artificial soil on untreated and treated fabric with finishes in combination

\begin{tabular}{lll}
\hline \multirow{2}{*}{ Treatments } & \multicolumn{2}{l}{ Fabric code } \\
\cline { 2 - 3 } & P/C-p & P/C-t \\
\hline Untreated & 62.86 & 64.88 \\
OA & 68.43 & 65.8 \\
OB & 60.9 & 59.67 \\
OC & 48.65 & 44.81 \\
OD & 37.22 & 41.67 \\
\hline
\end{tabular}

$\mathrm{O}_{\mathrm{A}}$, Commercial UV absorber at I\% add-on+Carboxymethyl cellulose at I\% add-on; $O_{B}$, Commercial UV absorber at I\% add-on+Commercial soil-release finishes; $\mathrm{O}_{C}$, Acacia catechu dyed at $4 \%$ shade+Carboxymethyl cellulose at I\% add-on; $O_{D}$, Acacia catechu dyed at $4 \%$ shade+Commercial soil-release finishes

Percent soil-release property: Soil-release is the term used for finish, which allows the soil to penetrate the fabric during wear, but it comes into action during washing when its special functional groups transfer the soil from the fabric to the washing liquor. All the four finish combination gave better percent soil release as compared to untreated fabrics.

It was also observed from Table 6 that after the application of $\mathrm{O}_{\mathrm{A}}$ i.e. $\mathrm{UV}$ absorbers $+\mathrm{CMC}$ percent soil-release noticeably increased in both the weaves as compared to the application of $\mathrm{O}_{\mathrm{B}}$ i.e. UV absorber+commercial soil-release finished. The reasons for this may be that $\mathrm{CMC}$ when applied it physically block the surface of the fabric there by preventing the soil particulate from penetrating into the fabric. This helps in removing the soil easily during laundering. The soil-release performance of the Acacia catechu with $\mathrm{CMC}\left(\mathrm{O}_{\mathrm{C}}\right)$ showed maximum value as compared to the other combination for both the fabric. It was expected because they picked up less soil as compared to commercial UV absorber with commercial soil-release finish.

Percent soil-redeposition characteristics: Soil-redeposition may be defined as deposition of soil which has already been released from the fabric during washing of fabrics. The fabric treated with the same chemical composition was stitched and laundered alone with soiled fabric of same chemical composition, to evaluate the soil-redeposition.

All the combination gave good readings for percent soil-redeposition and it was seen from the Table 7 that after treatments the percent soil-redeposition was considerably reduced when compared with the untreated fabric samples. The least soil-redeposition occurred with the combination of acacia catechu and $\mathrm{CMC}\left(\mathrm{O}_{\mathrm{C}}\right), 1.18$ and 1.44 in plain and twill weave respectively.

SEM studies of untreated and treated polyester/cotton twill weave soiled fabrics before and after laundry: The Scanning Microscopic studies were carried out to examine the effect of finishes on the fiber surface characteristics, soil affinity, and location of soiled area in the fabric and distribution of soil on the surface area of fiber which has been shown in Figure 2.
The Scanning Microscopic studies showed that in the case of untreated polyester/cotton blend twill weave fabric, much larger amount of soil particles were ambient forming clusters and hills on the fiber surface Figure 2c, where as in the case of combination of U.V absorber and CMC treated $\left(\mathrm{O}_{\star}\right)$ fabric, such detrimental effect was not visible, soil was distributed evenly on the fiber surface and fibrous structure Figure 2d.

Table 6 Percent soil-release after laundering (3cylces) of untreated and treated fabrics with finishes in combination

\begin{tabular}{lll}
\hline Treatments & \multicolumn{2}{l}{ Fabric code } \\
& P/C-p & P/C-t \\
\hline Untreated & 20.11 & 9.87 \\
SAB & 34.82 & 20.41 \\
OA & 43.64 & 33.91 \\
OB & 34.56 & 26.74 \\
SC & 26.1 & 20 \\
OC & 77.3 & 57.93 \\
OD & 60.55 & 50.24 \\
\hline
\end{tabular}

$\mathrm{S}_{\mathrm{AB}}$, Commercial soil-release finishes; $\mathrm{S}_{C}$, Carboxymethyl cellulose at $\mathrm{I} \%$ addon; $\mathrm{O}_{\mathrm{A}}$, Commercial UV absorber at I\% add-on+Carboxymethyl cellulose at $\mathrm{I} \%$ add-on; $\mathrm{O}_{B}$, Commercial UV absorber at $1 \%$ add-on+Commercial soil-release finishes; $O_{C}$, Acacia catechu dyed at $4 \%$ shade+Carboxymethyl cellulose at $1 \%$ add-on; $\mathrm{O}_{\mathrm{D}}$, Acacia catechu dyed at $4 \%$ shade+Commercial soil-release finishes

Untreated fabric after laundering shows that surface area was much uniform but the fibrous structure still contains some soil particles, it was not completely removed Figure 2e. In case of treated fabric with combination $\mathrm{O}_{\mathrm{A}}$ when washed greater was the release of soil from the fabric and increase the brightness Figure 2f.

Table 7 Percent soil-redeposition during laundering of on untreated and treated fabric with finishes in combination

\begin{tabular}{lll}
\hline \multirow{2}{*}{ Treatments } & \multicolumn{2}{l}{ Fabric code } \\
\cline { 2 - 3 } & P/C-p & P/C-t \\
\hline Untreated & 18.07 & 16.26 \\
SAB & 24.57 & 16.53 \\
OA & 5.24 & 1.41 \\
OB & 6.54 & 2.71 \\
SC & 21.65 & 16.21 \\
OC & 1.18 & 1.44 \\
OD & 2.42 & 2.63 \\
\hline
\end{tabular}

$\mathrm{S}_{\mathrm{AB}}$, Commercial soil-release finishes; $\mathrm{S}_{\mathrm{C}}$, Carboxymethyl cellulose at $\mathrm{I} \%$ addon; $\mathrm{O}_{\mathrm{A}}$, Commercial UV absorber at I\% add-on+Carboxymethyl cellulose at $1 \%$ add-on; $O_{B}$, Commercial UV absorber at $1 \%$ add-on+Commercial soil-release finishes; $O_{C}$, Acacia catechu dyed at $4 \%$ shade+Carboxymethyl cellulose at $1 \%$ add-on; $O_{D}$, Acacia catechu dyed at $4 \%$ shade+Commercial soil-release finishes. 


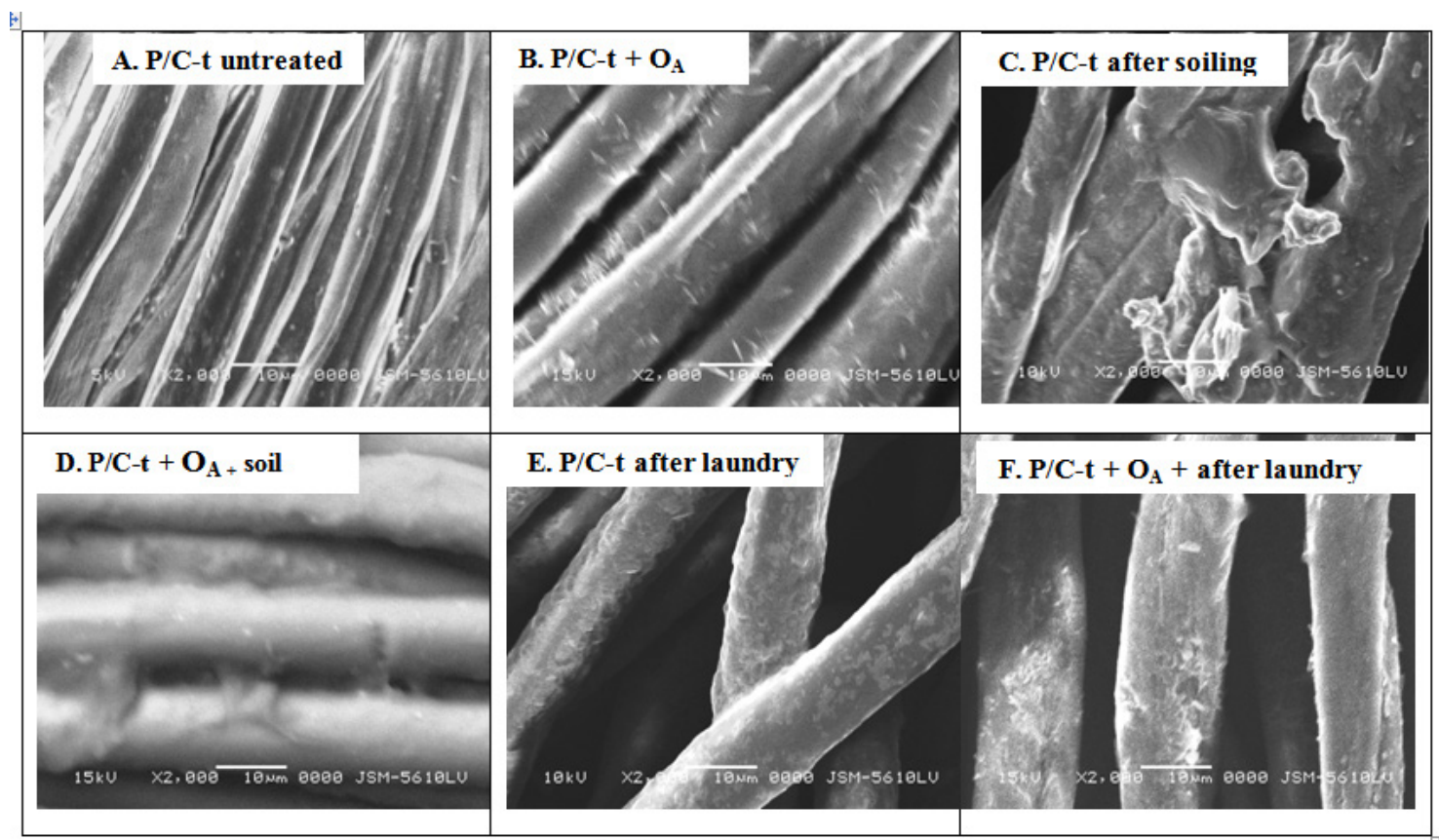

Figure 2 S.E.M images of the untreated treätéd with combination $\mathrm{O}_{\mathrm{A}}{ }^{\mathrm{P}} \mathrm{P} / \mathrm{C}$ blend twill samples soiled fabrics before and after faundry.

\section{Conclusion}

The influences of fabric parameters and UV absorbers and soil-release finishing, on UVR transmission, soil-release and soilredeposition were examined on $\mathrm{P} / \mathrm{C}$ blend (67/33). It was concluded from the study that

a. Fiber content was an important factor followed by weaves types, weight per unit area, fabric count, cloth cover and thickness of the fabric in predicting the percent UVR transmission.

b. Compact fabric construction offers higher protection to UV rays, as compared to lighter ones. It was seen that twill weave fabrics compared to plain weave showed lower UVR transmission.

c. All fabrics exhibited increase in percent UVR transmission when wet with artificial perspiration.

d. After laundering all samples showed reduced percent transmission. This could be attributed to the swelling and shrinkage of fabrics.

e. All the four finishing treatments studied were durable to laundry and showed good wash fastness

f. Treated plain weave fabrics released more soil after laundering as compared to the twill weave fabric.

g. The application of $\mathrm{O}_{\mathrm{A}}$ (Commercial UV absorbers with $\mathrm{CMC}$ ), noticeably improve the soil-release response in both the fabrics. The result shows that maximum redeposition of soil on untreated fabrics as compared to treated fabrics. h. Combination of Acacia catechu with $\mathrm{CMC}\left(\mathrm{O}_{\mathrm{C}}\right)$ gave maximum protection against $\mathrm{UV}$ rays as well it remove maximum soil after laundering.

i. It can be theorized that clothing constructed from polyester/cotton blend, treated with Acacia catechu and CMC could provide protection against UV radiation and soiling. Hence these treated fabrics with finishes in combination would be useful for clothing of outdoor workers.

\section{Acknowledgements}

None.

\section{Conflict of interest}

Author declares there is no conflict of interest in publishing the article.

\section{References}

1. Capajack, L, Kerr N, Davis S, et al. Protection of humans from Ultraviolet radiation through the use of textiles: A Review. Family \& consumer sciences res $J$. 1994;23(2):198-218.

2. Rieker J, Guschlbauer T, Rusmich S. Scientific and practical assessment of UV protection. Melliand textilberichte. 2001;78:E155-E156.

3. Cooke TF. Soil Release finishes for fibers and fabric. Textile Research J. 1983;31-41.

4. Nair GP. Studies in continuous dyeing-III, processing of polyester/cotton OG suiting for uniforms. Colourage. 2007;64-66. 